\title{
The association of incident dementia with mortality in PD
}

\author{
G. Levy, MD; M.-X. Tang, PhD; E.D. Louis, MD, MS; L.J. Côté, MD; B. Alfaro, MA; H. Mejia, MA; \\ Y. Stern, PhD; and K. Marder, MD, MPH
}

\begin{abstract}
Objective: To evaluate the association of incident dementia with mortality in a cohort of patients with idiopathic PD who were nondemented at baseline evaluation, controlling for extrapyramidal sign (EPS) severity at each study visit. Background: The development of dementia has been associated with reduced survival in PD. Because EPS severity is associated with both dementia and mortality in PD, the association of dementia with mortality may be confounded by disease severity. Methods: A cohort of patients with PD was followed annually with neurologic and neuropsychological evaluations. The association of incident dementia and the total Unified PD Rating Scale (UPDRS) motor score with mortality in PD was examined using Cox proportional hazards models with time-dependent covariates. All analyses were adjusted for age at baseline, sex, years of education, ethnicity, and duration of PD. Results: Of 180 PD patients, $41(22.8 \%)$ died during a mean follow-up period of $3.9 \pm 2.2$ years. Among those who died during the study period, $48.8 \%$ (20 of 41) became demented during follow-up, as compared to $23.0 \%$ (32 of 139) of those who remained alive. Both incident dementia (RR: 2.2, 95\% CI: 1.1 to $4.5, p=0.04$ ) and the total UPDRS motor score at each study visit (RR: 1.04, 95\% CI: 1.02 to $1.07, p=0.001$ ) were associated with mortality in PD when included in the same Cox model. Conclusions: Incident dementia has an independent effect on mortality when controlling for EPS severity. The development of dementia is associated with a twofold increased mortality risk in PD.
\end{abstract}

NEUROLOGY 2002;59:1708-1713

The development of dementia has been associated with reduced survival in patients with idiopathic PD. ${ }^{1-5}$ Because severity of extrapyramidal signs (EPS) is associated with both dementia ${ }^{6-9}$ and mortality $^{5,10-12}$ in $\mathrm{PD}$, the association of dementia with mortality in PD may be confounded by disease severity as measured by EPS. We have previously shown that when patients with PD were stratified by EPS severity at baseline evaluation, the occurrence of dementia at baseline or during follow-up contributed to mortality among those who had low EPS score, but not among those who had high EPS score, suggesting that EPS severity at baseline might be a more important predictor of mortality than the development of dementia. ${ }^{11}$

In the current study, we have examined the association of dementia with mortality in PD in the same cohort, using a subsample of the patients and a different analytical approach. Because all patients were nondemented at baseline evaluation, we assessed the association of incident rather than prevalent dementia with mortality in PD. The analysis controlled for severity of EPS at each study visit, which takes into account changes over time and provides a more accurate assessment of the contribution of EPS severity to mortality in PD.
Methods. Patients and procedures. A cohort of patients with PD from the Washington Heights community in northern Manhattan, NY, was followed annually, beginning in 1988, with neurologic and neuropsychological evaluations. The ascertainment procedure and inclusion and exclusion criteria for the cohort have been previously described..$^{13}$ Patients were identified through the development of a registry for $\mathrm{PD}$ in the community for all individuals considered to have PD or a related disorder. This population-based PD cohort included, but was not limited to, all patients living in the community who received their care at the Columbia Presbyterian Medical Center. Patients were identified from many sources including admission and discharge lists from the hospital, lists from various ambulatory care sites, and practitioners both in the hospital and in the community.

Idiopathic PD was defined by clinical and research criteria. ${ }^{14-16}$ Patients with postencephalitic and druginduced parkinsonism or a Parkinson-plus syndrome were excluded, as were patients who presented memory loss or dementia before the motor manifestations of PD. Of 319 patients with idiopathic PD, 105 considered to be demented at baseline evaluation were excluded from this analysis. Of 214 nondemented patients, 31 had no follow-up visit. These 31 patients with no follow-up were less likely to be white/non-Hispanic $(25.8 \%$ vs $54.6 \%, p<$ $0.05)$ than the patients with follow-up $(\mathrm{n}=183)$. No significant differences were observed for age, sex, years of edu-

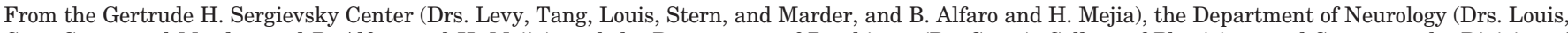

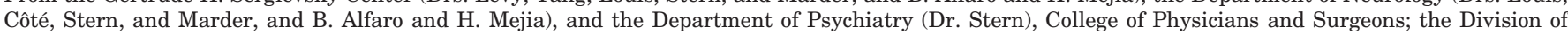

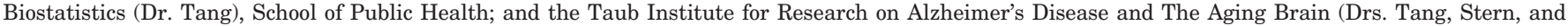
Marder), Columbia University, New York, NY.

Supported by federal grants AG10963, AG07232, RR00645, and NS36630, and the Parkinson's Disease Foundation.

Received April 29, 2002. Accepted in final form August 16, 2002.

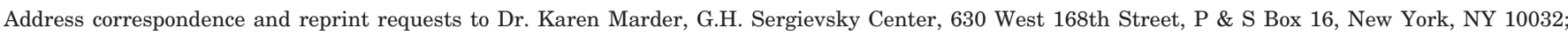
e-mail: marderk@sergievsky.cpmc.columbia.edu 
cation, duration of PD, or severity of EPS. Three additional patients were excluded because they had signs or symptoms of stroke at baseline, leaving 180 patients with at least two visits for the current analysis. Duration of PD was defined as the time period between the first symptom of $\mathrm{PD}$ and the baseline evaluation.

Data collection was performed blind to data collected in previous visits and dementia status. The annual clinical evaluation included parts I (mentation, behavior, and mood), II (activities of daily living), and III (motor examination) of the Unified PD Rating Scale (UPDRS). ${ }^{17}$ Use of antiparkinsonian medications, presence of signs or symptoms of stroke, and history of hypertension, diabetes mellitus, or heart disease (including myocardial infarction, congestive heart failure, valvular heart disease, angina, atrial fibrillation, or other cardiac arrhythmias) were recorded at each study visit. The validity of reporting of hypertension, diabetes mellitus, and heart disease compared to medical chart information has been examined in the same community. ${ }^{18}$

The annual neuropsychological evaluation included tests of verbal and nonverbal memory, orientation, visuospatial ability, language, and abstract reasoning. ${ }^{19}$ Neuropsychological test scores were evaluated using a fixed paradigm $^{19}$ and dementia was diagnosed based on the criteria of the Diagnostic and Statistical Manual of Mental Disorders, revised third edition (DSM-III-R). ${ }^{20}$ Each patient was assigned a Clinical Dementia Rating $(\mathrm{CDR})^{21}$ at each study visit. Nondemented patients had either CDR 0 (no dementia) or CDR 0.5 (questionable dementia), whereas demented patients were assigned CDR scores of 1 or more. Information about where subject was living (home, nursing home, hospital, rehabilitation center, other) was collected at each study visit. Death information was obtained from the following sources: family, hospital records, death certificates, autopsy reports, and death records of the National Death Index. Causes of death were known for 20 out of the 41 deceased patients during the study period.

Data analysis. Baseline characteristics of patients who died and those who remained alive during the study period were compared using Student's $t$-test for continuous variables and $\chi^{2}$ test or Fisher exact test for categorical variables. The association of incident dementia with mortality in PD was analyzed using Cox proportional hazards models with time-dependent covariates. ${ }^{22}$ Duration of follow-up from baseline until death or until the last visit for those patients who remained alive during the study period was used as the timing variable in the Cox models. All analyses adjusted for age at baseline, sex, years of education, ethnicity, and duration of PD. The Cox proportional hazards model with time-dependent covariates takes into account changes in predictor variables at each study visit (e.g., a patient may be nondemented at the first two visits and demented at the third visit or a patient may have a total UPDRS motor score of 10 at one visit and 15 at a subsequent visit). Because all patients were nondemented at baseline evaluation, any patient who met DSMIII-R criteria for dementia at any study visit represents an incident dementia case.

The total UPDRS motor score (range: 0 to 100) was calculated by summing the ratings (range: 0 [absent or normal] to 4 [most severe impairment]) of 25 items of the
UPDRS motor examination (part III). We also analyzed the association of six motor domains of the UPDRS with mortality in PD. The six motor domains included facial expression, tremor, rigidity, bradykinesia, speech, and axial impairment (gait, postural stability, posture, arising from a chair). ${ }^{23}$ Although the grouping of the items of the UPDRS motor examination to six domains was based on the cardinal clinical manifestations of PD rather than on a data-driven approach, a principal component factor analysis (varimax rotation) produced six factors with eigenvalues greater than 1 that broadly corresponded to the clinically defined motor domains.

In supplementary analyses, we evaluated other factors that might confound the association of incident dementia with mortality in PD as time-dependent covariates. These factors included medication use, vascular disease, nursing home placement, hallucinations, and depressive symptoms. For hallucinations and depressive symptoms, we defined categorical variables based on cutoff values of the ratings (range: 0 [none or normal] to 4 [most severe impairment]) of the items thought disorder and depression of the UPDRS (part I). Two categorical variables were defined for each item based on a more or less stringent cutoff value. Thought disorder (1) was considered to be present if a patient had a rating of 2 ('benign' hallucinations with insight retained") or more, and thought disorder (2) was considered to be present if a patient had a rating of 3 ("occasional to frequent hallucinations or delusions; without insight; could interfere with daily activities") or more. Depression (1) was considered to be present if a patient had a rating of 2 ("sustained depression [1 week or more]") or more, and depression (2) was considered to be present if a patient had a rating of 3 ("sustained depression with vegetative symptoms [insomnia, anorexia, weight loss, loss of interest]") or more.

In the Cox model with time-dependent covariates, a missing value for a time-dependent covariate in one study visit leads to the complete loss of the case in the analysis. In order to prevent missing the total information provided by a case due to a missing value for a variable in one annual visit, we carried over information on a categorical variable (e.g., dementia) of the previous visit to the visit with missing information. For continuous variables (e.g., total UPDRS motor score), we input the mean of the previous and subsequent visits. For each time-dependent covariate, the proportion of missing data ranged from 5 to $10 \%$ of the total number of visits for all patients in the cohort (895 visits).

Results. Of 180 patients with PD, 41 (22.8\%) died during a mean follow-up period of $3.9 \pm 2.2$ years. Patients who died during the study period were significantly older, less often Hispanic, and had higher total UPDRS motor score at baseline evaluation than those who remained alive. History of heart disease and ever smoking were significantly more frequent among those who died. Use of selegiline at baseline was not reported among those who died and was reported by $12.9 \%$ of those who remained alive (Fisher exact test, $p=0.01$ ). Estrogen replacement therapy in women was not reported among those who died and was reported by $17.7 \%$ of those who remained alive (Fisher exact test, $p=0.07$ ) (table 1 ). Fifty-two (28.9\%) patients became demented during follow-up. Among those who died, $48.8 \%$ (20 of 41 ) became demented during follow-up, 
Table 1 Baseline demographic and clinical characteristics of patients with PD who died during the study period and those who remained alive

\begin{tabular}{|c|c|c|c|}
\hline Variable & Deceased, $\mathrm{n}=41$ & Alive, $\mathrm{n}=139$ & Total, $\mathrm{n}=180$ \\
\hline Age, $\mathrm{y}^{*}$ & $75.9(8.7)$ & $69.6(10.3)$ & $71.0(10.3)$ \\
\hline Education, y & $10.8(4.6)$ & $11.2(4.8)$ & $11.1(4.8)$ \\
\hline$\%$ Male & 58.5 & 42.4 & 46.1 \\
\hline \multicolumn{4}{|l|}{ Ethnicity, \%* } \\
\hline White non-Hispanic & 68.3 & 51.8 & 55.6 \\
\hline Black non-Hispanic & 14.6 & 7.2 & 8.9 \\
\hline Hispanic & 17.1 & 41.0 & 35.6 \\
\hline Primary language, \% English* & 80.0 & 56.5 & 61.8 \\
\hline Duration of PD, y & $7.6(8.8)$ & $5.9(6.2)$ & $6.3(6.9)$ \\
\hline Total UPDRS motor score, range $0-100^{*}$ & $30.4(15.1)$ & $23.4(11.6)$ & $25.0(12.8)$ \\
\hline Total 17-item HDRS score, range 0-53 & $7.5(5.9)$ & $5.6(4.8)$ & $6.1(5.1)$ \\
\hline Use of levodopa, \% & 63.4 & 75.5 & 72.8 \\
\hline Use of dopaminergic agonists, \% & 35.0 & 26.1 & 28.1 \\
\hline Use of anticholinergics, $\%$ & 13.5 & 16.5 & 15.9 \\
\hline Use of selegiline, \%* & 0 & 12.9 & 10.0 \\
\hline Levodopa dosage, mg/d & $377.1(484.8)$ & $347.4(317.4)$ & $354.1(360.6)$ \\
\hline Hypertension, \% & 41.5 & 36.7 & 37.8 \\
\hline Diabetes mellitus, $\%$ & 10.0 & 8.0 & 8.4 \\
\hline Heart disease, $\% * \dagger$ & 53.7 & 20.1 & 27.8 \\
\hline Ever smoking, \%* & 60.0 & 40.1 & 44.6 \\
\hline At least one $A P O E \varepsilon 4$ allele, $\%$ & 22.7 & 23.4 & 23.3 \\
\hline Estrogen replacement therapy, \%* & 0 & 17.7 & 14.6 \\
\hline
\end{tabular}

Values are mean (SD) or \%. Total n: 178 for language, 177 for UPDRS score, 154 for HDRS score, 178 for use of dopaminergic agonists, 176 for use of anticholinergics, 159 for levodopa dosage, 178 for diabetes mellitus, 177 for ever smoking, 133 for APOE genotype, and 96 for estrogen replacement therapy.

$* p<0.05$ for the comparison deceased vs alive.

$\dagger$ Includes myocardial infarction, congestive heart failure, valvular heart disease, angina, atrial fibrillation, and other cardiac arrhythmias.

UPDRS = Unified Parkinson's Disease Rating Scale; HDRS = Hamilton Depression Rating Scale.

as compared to $23.0 \%$ (32 of 139) of those who remained alive ( $\chi^{2}$ test, $\left.p=0.001\right)$.

In a Cox model adjusting for age at baseline, sex, years of education, ethnicity, and duration of $\mathrm{PD}$, incident dementia was associated with an increased mortality risk (RR: $3.7,95 \% \mathrm{CI}: 2.0$ to $7.2, p<0.001$ ). When we included the CDR score at each study visit instead of incident dementia in the model, we observed increasing mortality risk with higher CDR score. In a separate model, the total UPDRS motor score at each study visit was also associated with an increased mortality risk (RR: $1.06,95 \% \mathrm{CI}: 1.03$ to 1.08, $p<0.001$ ). When both incident dementia and EPS severity were analyzed in a Cox model, both incident dementia (RR: $2.2,95 \% \mathrm{CI}: 1.1$ to $4.5, p=0.04$ ) and the total UPDRS motor score at each study visit (RR: $1.04,95 \% \mathrm{CI}$ : 1.02 to $1.07, p=0.001$ ) were associated with mortality in PD (table 2, models 1 to 4).

Among the specific motor domains of the UPDRS (facial expression, tremor, rigidity, bradykinesia, speech, and axial impairment), all except tremor were significantly associated with mortality in PD when included in separate Cox models. However, when included in the same model, only axial impairment was significantly associated with mortality in PD. When we reevaluated the association of incident dementia with mortality in PD controlling for axial impairment, incident dementia was still associated with a twofold increased mortality risk, but this result did not reach significance (see table 2, models 5 and 6).

Supplementary analysis. We performed supplementary analyses designed to evaluate other possible confounders in the association of incident dementia with mortality in PD. To explore the possibility that the association of dementia with mortality was related to withdrawal of levodopa (due to increased psychiatric side effects $)^{24}$ or to a hypothetical protective effect of selegiline on disease progression, ${ }^{25,26}$ which might both delay the development of dementia and increase survival, we repeated the analysis controlling for use of levodopa and use of selegiline as time-dependent covariates in different models. However, neither use of levodopa nor use of selegiline accounted for the association of incident dementia with mortality in PD.

The association of incident dementia with mortality was unchanged when signs or symptoms of stroke and history 
Table 2 Association of incident dementia with mortality in PD controlling for the UPDRS motor examination (part III)*

\begin{tabular}{|c|c|c|c|}
\hline Model & $\begin{array}{l}\text { Time-dependent } \\
\text { covariates }\end{array}$ & $\mathrm{RR}(95 \% \mathrm{CI})$ & $p$ Value \\
\hline 1 & Incident dementia & $3.7(2.0$ to 7.2$)$ & $<0.001$ \\
\hline \multirow[t]{5}{*}{2} & CDR 0 (reference) & 1 & - \\
\hline & $\begin{array}{l}\text { CDR } 0.5 \text { (questionable } \\
\text { dementia) }\end{array}$ & $1.2(0.4$ to 3.5$)$ & 0.7 \\
\hline & CDR 1 & $3.6(1.6$ to 8.2$)$ & 0.002 \\
\hline & CDR 2 & $4.3(1.4$ to 13.8$)$ & 0.01 \\
\hline & CDR 3 or 4 & $5.0(1.8$ to 14.0$)$ & 0.002 \\
\hline 3 & $\begin{array}{l}\text { Total UPDRS motor } \\
\text { score }\end{array}$ & $1.06(1.03$ to 1.08$)$ & $<0.001$ \\
\hline \multirow[t]{2}{*}{4} & Incident dementia & $2.2(1.1$ to 4.5$)$ & 0.04 \\
\hline & $\begin{array}{l}\text { Total UPDRS motor } \\
\text { score }\end{array}$ & $1.04(1.02$ to 1.07$)$ & 0.001 \\
\hline \multirow[t]{6}{*}{5} & Speech & $1.37(0.88$ to 2.14$)$ & 0.2 \\
\hline & Facial expression & 0.80 (0.48 to 1.34$)$ & 0.4 \\
\hline & Tremor & $1.00(0.91$ to 1.09$)$ & 0.9 \\
\hline & Rigidity & 1.06 (0.96 to 1.17$)$ & 0.3 \\
\hline & Bradykinesia & $1.04(0.97$ to 1.13$)$ & 0.3 \\
\hline & Axial impairment & $1.12(1.01$ to 1.25$)$ & 0.03 \\
\hline \multirow[t]{2}{*}{6} & Incident dementia & $2.0(0.9$ to 4.4$)$ & 0.07 \\
\hline & Axial impairment & 1.16 (1.06 to 1.26$)$ & 0.001 \\
\hline
\end{tabular}

* All analyses adjusted for age at baseline, sex, years of education, ethnicity, and duration of PD.

CDR $=$ Clinical Dementia Rating; UPDRS = Unified Parkinson's Disease Rating Scale.

of hypertension, diabetes mellitus, or heart disease were included in the same Cox model. Because we have previously shown an association of smoking with incident dementia in $\mathrm{PD}^{18}$ and smoking was significantly more frequent in those who died compared to those who remained alive during the study period (see table 1), we repeated the analysis controlling for baseline information regarding smoking (ever vs never and current and past vs never). In this analysis, incident dementia was still significantly associated with mortality in PD and the strength of the association was similar. The frequency of having at least one $A P O E \in 4$ allele was similar in patients with $\mathrm{PD}$ who died and those who remained alive during the study period (see table 1), and the association of incident dementia with mortality did not change when the analysis was repeated controlling for this variable.

An association between nursing home placement and mortality in PD has been reported. ${ }^{27}$ In our cohort, only 6 out of 180 patients (3.3\%) lived in a nursing home at any time during the study period (one patient since the baseline study visit and one patient temporarily for one study visit). Of these, four were cases with incident dementia and two died during the study period (both with incident dementia). When nursing home placement and incident dementia were included in a Cox model as time-dependent covariates, the association of incident dementia with mortality in PD did not change.

Neither the thought disorder nor the depression item from the UPDRS (part I) was significantly associated with dementia in PD using both definitions (see Methods), and the association of incident dementia with mortality in PD did not change when controlling for thought disorder and depression as time-dependent covariates. A subset of the cohort was evaluated with the Hamilton Depression Rating Scale. ${ }^{28}$ There was no significant difference in the total Hamilton Depression Rating Scale score at baseline between patients with PD who died and those who remained alive during the study period (see table 1), and the inclusion of this variable in a Cox model did not substantially change the association of incident dementia with mortality in PD.

Discussion. In this study, the development of dementia was associated with a twofold increased mortality risk in PD, after controlling for the total UPDRS motor score at each study visit. Incident dementia had an independent effect on mortality when controlling for disease severity as measured by EPS and other factors that might confound the association of dementia with mortality in PD such as medication use, vascular disease, nursing home placement, hallucinations, and depressive symptoms. The finding of independent effects of EPS severity and dementia on mortality in PD mirrors the observation of independent effects of parkinsonian signs and severity of cognitive impairment on mortality in $\mathrm{AD} .{ }^{29-31}$ The association of axial motor impairment with mortality in PD is consistent with previous studies showing decreased survival in patients with PD with gait and postural impairment or who had reached Hoehn \& Yahr stage III.,5,12 This finding is also supported by studies showing an association of gait impairment ${ }^{32,33}$ and falls ${ }^{34}$ with mortality in the elderly. When axial impairment was adjusted for in the analysis, the risk for dementia was twofold, but not significant ( $p=0.07$ ). We believe this may be due to limited statistical power in this study.

Some studies have evaluated the association of dementia with mortality in PD while controlling for EPS severity at baseline only., ${ }^{3,411,35}$ In a study following 34 patients with PD with cognitive impairment matched by age, sex, disease duration, and disease severity to 34 patients without cognitive impairment for 7 years, $33.3 \%$ of those with intellectual impairment and $12.5 \%$ of those without cognitive impairment died during follow-up, and a significantly higher percentage of deaths were observed in patients with more severe dementia. ${ }^{4}$ In two multivariate analyses of predictors of mortality in $\mathrm{PD}$, cognitive impairment as measured by a 10 -question mental status questionnaire was a significant predictor of mortality in a community-based study in Aberdeen, Scotland, ${ }^{3}$ whereas dementia was not a significant predictor of mortality in the context of a multicenter clinical trial in Sydney, Australia. ${ }^{35}$

Before levodopa therapy became available, PD had been associated with a threefold increased mortality compared to controls. ${ }^{36}$ Studies performed on cohorts of patients with PD on levodopa therapy have produced conflicting results. Some studies have 
shown no increased mortality risk compared to controls, ${ }^{37-42}$ whereas several other studies have demonstrated that patients with $\mathrm{PD}$ are at a 1.5 to 3.5 times significantly increased mortality risk compared to controls. ${ }^{10,11,35,43-53}$ It has been suggested that normal or near to normal mortality ratios in early studies following the introduction of levodopa therapy was due to levodopa delaying death in a group of older patients with PD. ${ }^{54}$ The range in mortality risks in different cohorts may also depend on disease severity and inclusion of demented patients.

Our study has limitations. The cohort consisted of individuals with a mean age at baseline of $71.0 \pm$ 10.3 years and the findings may not be applicable to a cohort of younger patients. Exclusion of patients with incomplete follow-up might have introduced a bias in the study sample, but no significant differences in age, sex, education, duration of PD, or EPS severity were observed between those with only the baseline evaluation and those with at least one follow-up visit. By including only incident dementia cases in our analysis, we were able to take into account the timing of the development of dementia in relation to mortality and to control for EPS severity at the time dementia developed. Conversely, by excluding cases without a dementia-free interval before the baseline evaluation, we may have excluded some cases with more rapidly progressive disease. We controlled for hallucinations and depressive symptoms using a four-point rating from the UPDRS (part I) rather than a comprehensive assessment of psychiatric symptomatology. Whereas previous studies have shown an association of depressive symptoms and hallucinations with dementia in $\mathrm{PD},{ }^{6,7}$ a recent study using the Rush Hallucination Inventory found no significant association of hallucinations with mortality in PD. ${ }^{55}$

In a mortality study performed after levodopa became available, patients with $\mathrm{PD}$ who eventually died benefited less from levodopa therapy than those who survived. ${ }^{10}$ Our finding that axial (gait and postural) impairment and dementia were associated with mortality in PD supports the suggestion that once non-levodopa responsive clinical characteristics appear, mortality in PD rises. ${ }^{35}$ Although the mechanism underlying the association of dementia with mortality in PD is unclear, we speculate that a widespread pathologic process involving both dopaminergic and nondopaminergic structures in late stages of the disease underlies dementia ${ }^{23}$ as well as swallowing $^{56}$ and autonomic ${ }^{57}$ dysfunction in PD.

\section{References}

1. Mindham RH, Ahmed SW, Clough CG. A controlled study of dementia in Parkinson's disease. J Neurol Neurosurg Psychiatry 1982;45:969-974.

2. Marder K, Leung D, Tang M, et al. Are demented patients with Parkinson's disease accurately reflected in prevalence surveys? A survival analysis. Neurology 1991;41:1240-1243.

3. Ebmeier KP, Calder SA, Crawford JR, Stewart L, Besson JA, Mutch WJ. Parkinson's disease in Aberdeen: survival after 3.5 years. Acta Neurol Scand 1990;81:294-299.
4. Piccirilli M, D’Alessandro P, Finali G, Piccinin GL. Neuropsychological follow-up of parkinsonian patients with and without cognitive impairment. Dementia 1994;5:17-22.

5. Roos RA, Jongen JC, van der Velde EA. Clinical course of patients with idiopathic Parkinson's disease. Mov Disord 1996;11:236-242.

6. Marder K, Tang MX, Cote L, Stern Y, Mayeux R. The frequency and associated risk factors for dementia in patients with Parkinson's disease. Arch Neurol 1995;52:695-701.

7. Stern Y, Marder K, Tang MX, Mayeux R. Antecedent clinical features associated with dementia in Parkinson's disease. Neurology 1993;43:1690-1692.

8. Hughes TA, Ross HF, Musa S, et al. A 10-year study of the incidence of and factors predicting dementia in Parkinson's disease. Neurology 2000;54:1596-1602.

9. Aarsland D, Andersen K, Larsen JP, Lolk A, Nielsen H, Kragh-Sorensen P. Risk of dementia in Parkinson's disease: a community-based, prospective study. Neurology 2001;56:730736.

10. Marttila RJ, Rinne UK, Siirtola T, Sonninen V. Mortality of patients with Parkinson's disease treated with levodopa. J Neurol 1977;216:147-153.

11. Louis ED, Marder K, Cote L, Tang M, Mayeux R. Mortality from Parkinson disease. Arch Neurol 1997;54:260-264.

12. Scigliano G, Musicco M, Soliveri P, et al. Mortality associated with early and late levodopa therapy initiation in Parkinson's disease. Neurology 1990;40:265-269.

13. Mayeux R, Denaro J, Hemenegildo N, et al. A populationbased investigation of Parkinson's disease with and without dementia. Relationship to age and gender. Arch Neurol 1992; 49:492-497.

14. Hughes AJ, Ben Shlomo Y, Daniel SE, Lees AJ. What features improve the accuracy of clinical diagnosis in Parkinson's disease: a clinicopathologic study. Neurology 1992;42:1142-1146.

15. Hughes AJ, Daniel SE, Kilford L, Lees AJ. Accuracy of clinical diagnosis of idiopathic Parkinson's disease: a clinicopathological study of 100 cases. J Neurol Neurosurg Psychiatry 1992;55:181-184.

16. Ward CD, Gibb WR. Research diagnostic criteria for Parkinson's disease. In: Streiffler MB, Korczyn AD, Melamed E, Youdim MB, eds. Parkinson's disease: anatomy, pathology and therapy. New York: Raven Press, 1990;245-249.

17. Stern MB. The clinical characteristics of Parkinson's disease and parkinsonian syndromes: diagnosis and assessment. In: Stern MB, Hurtig HI, eds. The comprehensive management of Parkinson's disease. New York: PMA Publishing, 1988;3-50.

18. Levy G, Tang MX, Cote LJ, et al. Do risk factors for Alzheimer's disease predict dementia in Parkinson's disease? An exploratory study. Mov Disord 2002;17:250-257.

19. Stern Y, Andrews H, Pittman J, et al. Diagnosis of dementia in a heterogeneous population. Development of a neuropsychological paradigm-based diagnosis of dementia and quantified correction for the effects of education. Arch Neurol 1992; 49:453-460.

20. American Psychiatric Association. Diagnostic and statistical manual of mental disorders, 3rd ed, rev. Washington, DC: American Psychiatric Press, 1987.

21. Hughes CP, Berg L, Danziger WL, Coben LA, Martin RL. A new clinical scale for the staging of dementia. Br J Psychiatry 1982;140:566-572.

22. Cox DR. Regression models and life-tables. J R Stat Soc B 1972;34:187-220.

23. Levy G, Tang MX, Cote LJ, et al. Motor impairment in PD: relationship to incident dementia and age. Neurology 2000;55: 539-544.

24. Mayeux R. A current analysis of behavioral problems in patients with idiopathic Parkinson's disease. Mov Disord 1989; 4(suppl 1):S48-S56.

25. Tetrud JW, Langston JW. The effect of deprenyl (selegiline) on the natural history of Parkinson's disease [see comments]. Science 1989;245:519-522.

26. Donnan PT, Steinke DT, Stubbings C, Davey PG, MacDonald TM. Selegiline and mortality in subjects with Parkinson's disease: a longitudinal community study [see comments]. Neurology $2000 ; 55: 1785-1789$. 
27. Goetz CG, Stebbins GT. Mortality and hallucinations in nursing home patients with advanced Parkinson's disease. Neurology 1995;45:669-671.

28. Hamilton M. A rating scale for depression. J Neurol Neurosurg Psychiatry 1960;23:56-62.

29. Stern Y, Tang MX, Albert MS, et al. Predicting time to nursing home care and death in individuals with Alzheimer disease [see comments]. JAMA 1997;277:806-812.

30. Bennett DA, Beckett LA, Wilson RS, Murray AM, Evans DA. Parkinsonian signs and mortality from Alzheimer's disease. Lancet 1998;351:1631.

31. Mitchell SL, Rockwood K. The association between parkinsonism, Alzheimer's disease, and mortality: a comprehensive approach. J Am Geriatr Soc 2000;48:422-425.

32. Bennett DA, Beckett LA, Murray AM, et al. Prevalence of parkinsonian signs and associated mortality in a community population of older people [see comments]. N Engl J Med 1996;334:71-76.

33. Wilson RS, Schneider JA, Beckett LA, Evans DA, Bennett DA. Progression of gait disorder and rigidity and risk of death in older persons. Neurology 2002;58:1815-1819.

34. Donald IP, Bulpitt CJ. The prognosis of falls in elderly people living at home. Age Ageing 1999;28:121-125.

35. Hely MA, Morris JG, Traficante R, Reid WG, O'Sullivan DJ, Williamson PM. The Sydney multicentre study of Parkinson's disease: progression and mortality at 10 years. J Neurol Neurosurg Psychiatry 1999;67:300-307.

36. Hoehn MM, Yahr MD. Parkinsonism: onset, progression and mortality. Neurology 1967;17:427-442.

37. Hoehn MM. Parkinsonism treated with levodopa: progression and mortality. J Neural Transm Suppl 1983;19:253-264.

38. Zumstein H, Siegfried J. Mortality among Parkinson patients treated with L-dopa combined with a decarboxylase inhibitor. Eur Neurol 1976;14:321-328.

39. Joseph C, Chassan JB, Koch ML. Levodopa in Parkinson disease: a long-term appraisal of mortality. Ann Neurol 1978;3: $116-118$.

40. Diamond SG, Markham CH. Present mortality in Parkinson's disease: the ratio of observed to expected deaths with a method to calculate expected deaths. J Neural Transm Gen Sect 1976;38:259-269.

41. Shaw KM, Lees AJ, Stern GM. The impact of treatment with levodopa on Parkinson's disease. Q J Med 1980;49:283-293.

42. Rajput AH, Offord KP, Beard CM, Kurland LT. Epidemiology of parkinsonism: incidence, classification, and mortality. Ann Neurol 1984;16:278-282.

43. Curtis L, Lees AJ, Stern GM, Marmot MG. Effect of L-dopa on course of Parkinson's disease. Lancet 1984;2:211-212.
44. Diamond SG, Markham CH, Hoehn MM, McDowell FH, Muenter MD. Multi-center study of Parkinson mortality with early versus later dopa treatment. Ann Neurol 1987;22:8-12.

45. Sweet RD, McDowell FH. Five years' treatment of Parkinson's disease with levodopa. Therapeutic results and survival of 100 patients. Ann Intern Med 1975;83:456-463.

46. Ben Shlomo Y, Marmot MG. Survival and cause of death in a cohort of patients with parkinsonism: possible clues to aetiology? J Neurol Neurosurg Psychiatry 1995;58:293-299.

47. Berger K, Breteler MM, Helmer C, et al. Prognosis with Parkinson's disease in Europe: a collaborative study of population-based cohorts. Neurologic Diseases in the Elderly Research Group. Neurology 2000;54(suppl 5):S24-S27.

48. Morens DM, Davis JW, Grandinetti A, Ross GW, Popper JS, White LR. Epidemiologic observations on Parkinson's disease: incidence and mortality in a prospective study of middle-aged men. Neurology 1996;46:1044-1050.

49. Morgante L, Salemi G, Meneghini F, et al. Parkinson disease survival: a population-based study. Arch Neurol 2000;57:507512.

50. Minami Y, Yamamoto R, Nishikouri M, Fukao A, Hisamichi S. Mortality and cancer incidence in patients with Parkinson's disease. J Neurol 2000;247:429-434.

51. Tison F, Letenneur L, Djossou F, Dartigues JF. Further evidence of increased risk of mortality of Parkinson's disease. J Neurol Neurosurg Psychiatry 1996;60:592-593.

52. Wermuth L, Stenager EN, Stenager E, Boldsen J. Mortality in patients with Parkinson's disease. Acta Neurol Scand 1995; 92:55-58.

53. Guttman M, Slaughter PM, Theriault M-E, DeBoer DP, Naylor CD. Parkinsonism in Ontario. Increased mortality compared with controls in a large cohort study. Neurology 2001; 57:2278-2282.

54. Clarke CE. Does levodopa therapy delay death in Parkinson's disease? A review of the evidence [see comments]. Mov Disord $1995 ; 10: 250-256$.

55. Goetz CG, Leurgans S, Pappert EJ, Raman R, Stemer AB. Prospective longitudinal assessment of hallucinations in Parkinson's disease. Neurology 2001;57:2078-2082.

56. Muller J, Wenning GK, Verny M, et al. Progression of dysarthria and dysphagia in postmortem-confirmed parkinsonian disorders [see comments]. Arch Neurol 2001;58:259-264.

57. Wenning GK, Scherfler C, Granata R, et al. Time course of symptomatic orthostatic hypotension and urinary incontinence in patients with postmortem confirmed parkinsonian syndromes: a clinicopathological study [see comments]. J Neurol Neurosurg Psychiatry 1999;67:620-623. 


\section{Neurology}

\section{The association of incident dementia with mortality in PD}

G. Levy, M.-X. Tang, E.D. Louis, et al.

Neurology 2002;59;1708-1713

DOI 10.1212/01.WNL.0000036610.36834.E0

This information is current as of December 10, 2002

\section{Updated Information \& \\ Services}

\section{References}

Citations

Subspecialty Collections

Permissions \& Licensing

\section{Reprints}

including high resolution figures, can be found at:

http://www.neurology.org/content/59/11/1708.full.html

This article cites 48 articles, 23 of which you can access for free at: http://www.neurology.org/content/59/11/1708.full.html\#\#ref-list-1

This article has been cited by 13 HighWire-hosted articles: http://www.neurology.org/content/59/11/1708.full.html\#\#otherarticles

This article, along with others on similar topics, appears in the following collection(s):

\section{All Cognitive Disorders/Dementia}

http://www.neurology.org//cgi/collection/all_cognitive_disorders_deme ntia

All epidemiology

http://www.neurology.org//cgi/collection/all_epidemiology

Case control studies

http://www.neurology.org//cgi/collection/case_control_studies

Parkinson's disease/Parkinsonism

http://www.neurology.org//cgi/collection/parkinsons_disease_parkinso nism

Information about reproducing this article in parts (figures,tables) or in its entirety can be found online at:

http://www.neurology.org/misc/about.xhtml\#permissions

Information about ordering reprints can be found online: http://www.neurology.org/misc/addir.xhtml\#reprintsus

Neurology ${ }^{\circledR}$ is the official journal of the American Academy of Neurology. Published continuously since 1951, it is now a weekly with 48 issues per year. Copyright . All rights reserved. Print ISSN: 0028-3878. Online ISSN: 1526-632X.

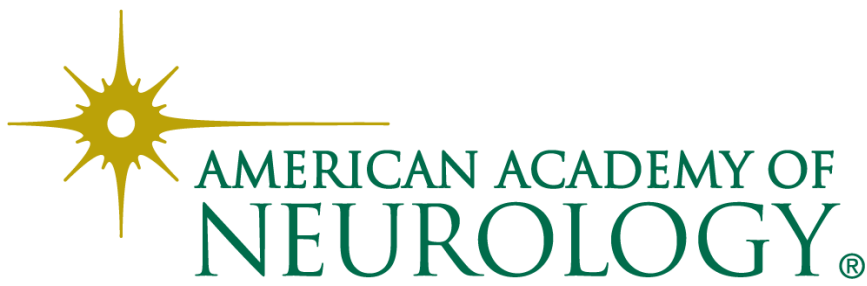

